\title{
SABERES DOCENTES E PROCESSOS FORMATIVOS
}

\author{
Prof. ${ }^{\mathrm{a}}$ Dr. ${ }^{\mathrm{a}}$ Neuza Bertoni PINTO *
}

\section{Resumo}

Este artigo objetiva discutir a formação do professor universitário, a partir de uma reflexão sobre a natureza e as características dos saberes docentes. Ao focalizar a pluralidade desses saberes, destacou-se o eixo estruturante dessa formação - os saberes da experiência- e a necessidade de uma formação pedagógica que supere 0 modelo de racionalidade técnica e investigue as relações de poder envolvidas nesses saberes, identificando, na práxis docente, os limites e as possibilidades da profissionalização docente frente ao papel da universidade e o atual projeto educacional brasileiro.

Palavras-chave : saberes docentes, professor universitário, formação docente, profissão docente.

\section{Resumen}

Este artículo tiene como objeto discutir la formación del profesor universitario a partir de una reflexión sobre la naturaleza y las características de los saberes docentes.

Al focalizar la pluralidad de esos saberes, se destacó el eje que estructura esa formación, los saberes de la experiencia y la necesidad de una formación pedagógica que supere el modelo de racionalidad técnica e investigue las relaciones de poder envueltas en esos saberes, identificando, en la praxis docente, los límites y las posibilidades de profesionalización docente frente a la función de la universidad y al actual projecto educacional Brasileño.

Palabras llave : saberes docentes, profesor universitario, formación docente, profesión docente.

* Professora Pesquisadora do Programa de Mestrado em Educação da PUCPR 
O debate sobre a formação do professor tem se deslocado, na última década, do patamar do ensino básico para o ensino superior e provocado no cenário brasileiro um movimento novo nas universidades em termos de mudanças necessárias e urgentes nos processos pedagógicos desenvolvidos nas salas de aula dos cursos de graduação. No momento em que a universidade passa a ser pressionada pela competitividade do mercado, enfrenta o desafio de tornar mais transparente sua proposta de trabalho e romper a zona de silêncio referente à formação profissional de seus docentes.

Hoje, o debate em torno do "saber" e do "saber-fazer" dos docentes do ensino superior abre-se para novas questões que envolvem não só o papel do professor universitário, como também o da própria universidade, enquanto instituição social responsável por processos formativos, suscitando novos posicionamentos sobre a profissionalidade docente.

Ao analisar a natureza dos saberes envolvidos nas práticas docentes do ensino superior, o objetivo deste artigo não é apenas tecer uma reflexão sobre estes saberes, mas sobretudo compreender o sentido do discurso das competências no contexto das mudanças que vêm ressignificando o papel da universidade brasileira.

\section{Epistemologia dos Saberes Docentes}

Inicialmente, ancoraremos a análise dos saberes docentes em dois artigos publicados pelo pesquisador canadense Maurice TARDIF $(1991,1999)$, em que foram discutidos os fundamentos epistemológicos da prática profissional docente. $\mathrm{O}$ eixo das discussões do autor centrou-se, primeiramente, na premissa de que a competência docente integra uma pluralidade de saberes; posteriormente, na primazia ocupada pelos saberes de experiência, em relação aos saberes oriundos da formação acadêmica.

No primeiro estudo, o autor identifica na práxis docente quatro modalidades de saberes: saberes de formação profissional, saberes disciplinares, saberes curriculares e saberes de experiência.

Os primeiros, saberes profissionais, referem-se ao conjunto de saberes contemplados pelas instituições de formação de professores. São saberes oriundos das ciências da educação em termos de teorias e concepções que possam orientar a prática educativa, portanto, produzidos para serem incorporados à formação profissional do professor. Seriam os saberes pedagógicos que o professor mobilizaria para atender a função da instituição escolar. Quantos, dentre os milhares de professores universitários brasileiros, buscaram essa preparação didática? ${ }^{1}$

Os saberes das disciplinas correspondem aos saberes situados nos diversos campos de conhecimento (matemática, literatura, história etc.), emer- 
gentes da tradição cultural e dos grupos sociais produtores de saberes. Dizem respeito à definição e seleção, realizadas pela universidade, dos saberes sociais, ou seja, a escolha da matéria-prima a ser trabalhada nos diferentes cursos oferecidos. De que forma os professores universitários têm participado dessa escolha?Quais concepções de educação, valores, atitudes, crenças, preconceitos estão influenciando tais escolhas?

Os saberes curriculares tratam dos discursos, objetivos, conteúdos e métodos contemplados pela universidade para a operacionalização dos saberes disciplinares, o processo de transformação e adequação dos "savoirs savants" em "savoirs scolaires", o que CHEVALLARD (1985) estudou como "transposição didática", ou seja, a passagem dos saberes científicos para saberes escolares. Para 0 autor dessa teoria, na cadeia da transposição didática, o saber não traz consigo a finalidade de ser ensinado, mas somente a necessidade de ser utilizado. É o projeto pedagógico que faz nascer uma dialética entre a "designação entre conteúdos de saberes e conteúdos de saberes a ensinar" (CHEVALLARD: 1985, p. 39). Quando os conteúdos a serem ensinados são escolhidos pelo professor, este saber sofre um conjunto de transformações (ou deformações!) adaptativas para torná-lo apto a ocupar um lugar entre os objetos de ensino. Trata-se do importante trabalho de preparação didática elaborada em vista da passagem desse objeto para a situação de ensino. É, de acordo com o autor, a entrada no texto do saber, o campo conceitual que delimita os conceitos nucleares do objeto em estudo. De que forma essas questões vêm sendo discutidas no ensino superior?

Por último, o autor acrescenta os saberes de experiência, fundados no trabalho cotidiano do professor e no conhecimento do seu meio. Tendo como ponto de partida os desafios que encontra na sua prática pedagógica, tais saberes, ao serem validados por ela, incorporam-se à prática profissional sob a forma de "habitus", termo proposto por Bourdieu para designar o conjunto de habilidades, hábitos e saber-fazer e saber-ser que vão configurando 0 "metiér" docente. O que sabemos dessa cultura pedagógica que tem um peso decisivo na atuação dos professores universitários? Que modelos didáticos foram incorporados e permanecem disponíveis para serem acionados nas emergências da práxis pedagógica?

A competência profissional, segundo TARDIF (1991), deve expressar todos esses domínios de saberes. Para ele:

O (a) professor (a) padrão é alguém que deve conhecer sua matéria, sua disciplina e o seu programa, que deve possuir certos conhecimentos das ciências da educação e da pedagogia, sem deixar de desenvolver um saber prático fundado em sua experiência cotidiana com os alunos. (TARDIF: 1991, 221). 
De todos os saberes, quais motivos levaram o autor a considerar os saberes da experiência como saberes fundamentais para a prática profissional, o "núcleo vital" dos saberes docentes, quando se trata de um saber pessoal, difícil de ser explicitado e impossível de ser generalizado?

Para esclarecer essa questão, encontramos, na segunda referência (TARDIF: 1999), uma nova ênfase da relevância de tais saberes, a ponto de 0 autor criticar o espaço prioritário, dispensado pelas agências formativas, ao saber didático e ao saber pedagógico, em seus programas de formação. Ao defender uma proposta que denomina de ecológica integrativa, o autor afirma:

A proposta ecológica integrativa deseja ampliar e ultrapassar as duas portas de entrada tradicionais da análise do ensino, que são a didática e a pedagogia ou a psicopedagogia; as quais foram durante muito tempo as duas tetas da formação de professores na universidade (TARDIF: 2000:19).

Observa-se, nesta afirmação, uma crítica severa ao reducionismo da didática que predominou (e ainda está presente) nas salas de aula da universidade, caracterizada por um saber-fazer restrito às dimensões técnicas e procedimentais do ensino. Para a comunidade educacional brasileira, essa didática instrumental, já colocada em questão no debate iniciado na década de 80 (CANDAU:1984), possibilitou que a educação, a pedagogia e a didática plantassem novos marcos de formação de professores, realizando grandes questionamentos a respeito das relações que fundamentam o ensino e a pesquisa no interior dos cursos de formação. Inúmeras publicações trataram, posteriormente, de mostrar os avanços dos conhecimentos didáticos e pedagógicos, em busca de propostas e soluções alternativas para um ensino comprometido com um projeto social transformador. Avanços igualmente importantes ocorreram em relação às pesquisas sobre formação profissional, trazendo novos enfoques acerca da identidade do professor e dos fatores que, ao longo dos séculos anteriores, obstacularizaram sua valorização profissional (NÓVOA:1993). Apesar de todo esse avanço teórico, ainda são raros os estudos que explicitam as mudanças que vêm ocorrendo (ou não) na práxis pedagógica universitária. Nesta direção, o sociólogo suíço PERRENOUD (1994), tem instigado uma leitura mais realística dos contextos formativos e das práticas docentes, trazendo observações e análises de aspectos rotineiros das práticas pedagógicas, ou seja, a realidade da dispersão do tempo, as implicações das mudanças das práticas avaliativas para o desequilíbrio das frágeis estruturas que sustentam a vida escolar, as manobras do aluno frente às práticas conservadoras e construtivistas, enfim, sinais de que a escola está passando por inúmeras transformações que merecem ser investigadas e melhor observadas pelos docentes. 
No entanto, a leitura dessa nova realidade tem permanecido restrita ao cotidiano do ensino básico. São raros e recentes os estudos que focalizam o cotidiano pedagógico universitário, especialmente, a investigação dos saberes pedagógicos dos docentes que atuam na universidade. Apesar da corrente reformista que tem perpassado a formação de professores e a renovação da educação, da pedagogia e da didática, tal necessidade toma-se mais real, quando se presencia 0 crescimento desordenado do ensino superior no país, em que na maioria das instituições de ensino superior os docentes são admitidos sob critérios pouco transparentes, com um ingresso feito de forma circunstancial.

Tal situação é mais preocupante quando encontramos na realidade brasileira as constatações de TARDIF (1991), de que o professor universitário tem incorporado à sua prática "saberes de segunda mão", saberes não provenientes dela, ou sejam, saberes não produzidos por ele. Ao manter uma relação de "transmissor" ou "depositário" de saberes, não controlados por ele, quer se trate de saberes curriculares, profissionais ou disciplinares, ao não ser produtor de saber, o professor acaba por deslegitimar sua própria prática profissional. Tal "relação de exterioridade", faz com que os professores, para serem competentes, se apropriem de saberes produzidos e legitimados por outros, pensados para outros contextos, quer se trate de saberes científicos ou pedagógicos.

No aprofundamento de suas pesquisas, TARDIF (1999) aborda características mais detalhadas dos saberes profissionais docentes, qualificando-os de: temporais, plurais, personalizados e situados. Saberes temporais se justificam no fato de os professores incorporarem, enquanto alunos, durante longos anos escolares, inúmeras representações do que é ser professor. Tais crenças, representações e certezas, trazidas na bagagem da vida escolar, são reativadas quando começam a trabalhar como professores. Outro sentido temporal dos saberes docentes diz respeito aos tateios e desafios enfrentados nos primeiros anos da docência, ocasiões de dúvidas e incertezas quanto ao preparo das aulas e busca de soluções para a problemática emergente da sala de aula. Essa fase de exploração e de sobrevivência profissional é decisiva em termos de aquisição de competência e estruturação da prática profissional. Quanto mais criação e empenho nesta fase, maior será o sentimento de competência e envolvimento na profissão. Um último aspecto temporal do saber docente é o tempo de experiência e o conhecimento das diferentes realidades institucionais; exercer a docência em diferentes instituições não só amplia 0 saber de experiência necessário para a sala de aula como também o saber viver numa escola.

A pluralidade dos saberes é mais um imperativo na prática docente. Em sua ação docente, o professor mobiliza não apenas saberes disciplinares relativos aos fundamentos dos conteúdos, sua veiculação nos manuais escolares, sua relação com as aspirações da sociedade, com o seu significado cultu- 
ral em relação à cultura dos alunos. Outros saberes são interligados à gestão do programa, tais como o de fazer o programa entrar em sintonia com 0 tempo de ensino disponível para o professor e o tempo de aprendizagem, disponibilizado pelo aluno; ao grupo-classe, em termos de interações, motivações, conhecimentos necessários para se compreender as relações de amor, simpatia, empatia, indiferença ou repulsão, que pode ligar, ou afastar, o aluno a um grupo e à própria instituição escolar. São inúmeros os objetivos que 0 professor administra, simultaneamente, numa sala de aula, devendo, para isto, mobilizar um extenso rol de saberes e habilidades, muitos deles retirados de sua caixa pessoal de ferramentas.

PERRENOUD (1994: 35) lembra que a prática pedagógica nunca é um conjunto de receitas. Mesmo em pedagogias mais fechadas, o professor coloca sua marca ao organizar e estruturar seus planos, ao escolher modos de trabalhar as lições, ao definir as atividades dos alunos, ao priorizar conceitos dentro de uma unidade horária, como também planejar a avaliação correspondente a cada modalidade de trabalho. Na pedagogia tradicional, este modo de fazer funcionar o ensino assemelha-se a to da organização burocrática, em que tudo é minuciosamente planejado para proteger o improviso. Quando se trata de uma pedagogia ativa, em que as atividades são mais abertas e menos estruturadas, tais como projetos, entrevistas, pesquisas, jogos, oficinas, trabalhos de grupos, a figura do professor "bricoleur" está presente, pelo fato de ter que administrar um grande número de tarefas diversificadas. No entanto, ao contrário do engenheiro, seu universo de trabalho não tem regras e materiais previamente detalhados, tendo que se valer, na maioria das vezes, dos recursos que têm às mãos; criar e improvisar diante de situações imprevistas são características fortes da profissão docente.

Nesse sentido, PERRENOUD (1996) lembra que ensinar é um "metiér" complexo, pelo fato de o professor ter que "agir na urgência e decidir na incerteza". Para esse autor, as competências docentes não se restringem à acumulação de conhecimentos, capacidades, mas dizem respeito ao saber mobilizar esses recursos.

O saber docente também é personalizado e situado. Sua natureza não é apenas cognitiva; traz as marcas da história vivida por seus atores, os traços de sua cultura, de seus pensamentos e construções pessoais, de seus contextos de trabalho, de suas experiências individuais, de seus talentos, de todos os embates de sucesso/insucesso já vividos existencialmente.

A competência existe quando se utiliza o repertório de recursos que dispomos em termos de conhecimentos, capacidades cognitivas, relacionais etc. para enfrentar os diferentes desafios colocados pelas práticas pedagógicas. Essa pluralidade de saberes que o professor utiliza tem fontes variadas, porém, tem uma natureza pragmática, deve estar a serviço da ação, ou seja, ter um significado e uma utilidade para o seu trabalho. 
Quando é solicitada indicação de competências docentes a professores universitários, de diferentes áreas de conhecimento, em geral são apontadas qualidades genéricas e abstratas em relação ao professor, tais como: paciência, criatividade, liderança, ética, intuição, flexibilidade, responsabilidade, perseverança, empatia etc. Raramente, são apontadas competências específicas do trabalho cotidiano da sala de aula, ou sejam: saber elaborar um projeto, saber trabalhar em equipe, saber planejar uma situação de aprendizagem, saber construir uma prova, saber avaliar uma tarefa, saber se comunicar com a classe, saber elaborar uma situação-problema, saber contextualizar, saber acompanhar o progresso dos alunos, saber buscar recursos para implementar projetos de trabalho, saber administrar o tempo do ensino, saber trabalhar com a heterogeneidade do grupo-classe, saber preparar um seminário, saber improvisar etc. Enfim, são lembradas e priorizadas competências aplicáveis às profissões de um modo geral, aquelas inscritas num conceito genérico de educador, ( pais, médicos, comunicadores etc.).

As especificidades mais objetivas da profissão (savoir-faire), raramente são lembradas. Em geral, essas escolhas refletem as representações que compõem o imaginário dos professores, ou seja, a imagem do educador como um ser moral: honesto, bondoso, solidário, abnegado, enfim, tudo que a sociedade construiu a respeito desse profissional ao longo de um história que não é necessariamente uma história da escola concreta. A competência não estaria centrada nas práticas de referência da profissão de origem, ou melhor em seus construtos sociais?

Nesse sentido, há que se considerar pertinente a observação de TARDIF (1999: 24) referente à impossibilidade dos profissionais das chamadas profissões de interação humana de poder apoiarem-se e produzirem dispositivos e tecnologias de controle de todas as situações de seu ambiente de trabalho. No magistério, como em outras profissões de interação humana, a personalidade é o mediador mais importante na interação.

Os saberes docentes são também saberes situados, em seus contextos de trabalho, requerendo negociação entre os atores envolvidos. $\mathrm{O}$ fato de o ser humano ser o objeto do trabalho docente explica a grande carga de sensibilidade requerida no trato com os alunos, em termos de suas diferenças individuais e culturais. Desenvolver essa sensibilidade requer um investimento a longo prazo, já que se trata de um saber eminentemente construído no âmbito da experiência profissional. Um componente de peso no rol dos saberes docente está sedimentado no campo ético. Toda educação está permeada por valores éticos. Tanto nos relacionamentos e nos julgamentos de valor que o professor realiza em relação à aprendizagem dos alunos estão envolvidos valores éticos e morais. $\mathrm{O}$ que dizer, por exemplo, de algumas práticas autoritárias de avaliação ainda vigentes na universidade? E da relações de poder não só entre professores e alunos, mas também entre o corpo administrativo e 
pedagógico da instituição escolar? Buscar competências dos professores nos remete ao debate da natureza práticas docentes. Mais do que buscá-las, não seria mais "formativo" analisar a gênese dos saberes que sustentam as práticas docentes, a partir das diferentes práticas sociais de referência, procurando compreender seus determinantes sociais?

A pesquisa desenvolvida por CUNHA e LEITE (1996) mostrou que os processos pedagógicos na universidade estão sujeitos às relações de poder da sociedade e como capital cultural esses rituais variam segundo o lugar que as profissões ocupam na organização social do trabalho. Revelou também que quanto maior é o capital cultural e econômico, que o conhecimento representa, mais herméticas são as condições de mudança e que seria ingênuo pensar mudanças de práticas pedagógicas sem uma reflexão sobre as especificidades de cada área de conhecimento e os mecanismos de controle a que está sujeita, não sendo, portanto, possível pensar uma pedagogia única para toda a universidade, já que os diferentes campos epistemológicos são diretamente definidos e controlados de formas desiguais pela sociedade.

\section{Tradições Formativas da Docência}

Há duas décadas, os Estados Unidos e a Europa vêm apresentando uma crescente preocupação com a formação docente, no sentido de fornecer aos professores maior autonomia, privilégios e estatuto. Nesses novos discursos, palavras como reflexão e poder de decisão estão na ordem do dia. Os pesquisadores europeus têm mostrado que a profissionalização é um constructo social, cujo conceito muda em função das condições sociais em que é utilizada, portanto, não tem uma definição fixa e universal, e nem é um termo neutro, pois, como oportunidade histórica, reflete como as profissões funcionam em determinados contextos e em determinados momentos histónicos.

Nesta perspectiva, a formação de professores passa a ser compreendida não como um lugar de aquisição de técnicas e de conhecimento, mas como um espaço de socialização e de configuração profissional.

A idéia de compreender a formação docente deslocando a discussão da perspectiva acadêmica para centralizá-la no terreno profissional é compartilhada por inúmeros pesquisadores, entre outros, NÓVOA (1992) quando coloca a necessidade de se pensar a profissão docente a partir de uma reflexão da história da formação de professores. Em Portugal, segundo este autor, as bases dessa profissão se deram mediante de lutas políticas entre a Igreja e o Estado. Ao longo do séc. XIX, a imagem que alí se tem da profissão é a do apostolado e do sacerdócio, dada a humildade e obediência dos professores. Segundo ele, a profissão docente foi se afirmando com uma identidade ambígua: 
"não deviam saber demais, nem de menos; não deviam se misturar com 0 povo, nem com a burguesia; não deviam ser pobres, nem ricos; não deveriam ser (bem) funcionários públicos, nem profissionais liberais" (Nóvoa: 1992: 16) .

Em Portugal, durante o Estado Novo, segundo NÓVOA, ao mesmo tempo que se assiste a degradação do estatuto sócioeconômico da profissão docente, consagra-se uma visão funcionarizada do professor. Mesmo a partir dos anos 60, em que a formação docente começava a ser questionada pelos movimentos sociais e políticos, o debate se concentrava em torno do estatuto da carreira docente, fortalecendo interesses corporativistas, e não avançando questões relativas à autonomia profissional. Prolongou-se, assim, uma tutela estatal sobre o professorado, tido como um corpo profissional sem capacidade de gerar autônomamente os seus próprios saberes. As políticas reformadoras ratificaram, por sua vez, essa imagem dos professores, aumentando a separação entre atores e decisores, por meio de controles mais sutis, como programas de formação em serviço orientados por uma visão conformista da profissão docente.

Nessa abordagem do panorama português encontramos indicadores para perceber como as universidades estão envolvidas nos modelos de racionalidade técnica implícito nos projetos avaliativos do Estado. Por um lado, a pressão da sociedade competitiva exigindo profissionais mais qualificados; por outro, propostas formativas que não estimulam uma crítica mais rigorosa do que é ser professor, de qual é sua verdadeira função numa sociedade competitiva, injusta e estratificada.

Segundo GÓMEZ (1992), é ingênuo afirmar que as instituições de formação preparam o futuro professor para enfrentar os desafios de sala de aula. Quando muito, o que faz é orientar, de forma muito limitada, sugerindo regras para ambientes protótipos e para aspectos comuns da vida escolar. A insegurança com que os principiantes iniciam suas práticas confirmam que a complexidade da tarefa educativa não pode ser compreendida no âmbito do conhecimento acadêmico, cada vez mais fragmentado e distanciado da realidade concreta.

A cisão entre a teoria e prática que se constata no interior dos cursos de formação inicial é uma herança herdada de contextos sociais mais amplos, cuja valorização da técnica reflete na discriminação entre as ciências exatas e humanas existente na própria sociedade. A escola, ao reproduzir as relações sociais, particularmente no currículo de formação de professores, acentua e reforça o abismo entre a teoria e prática. A prática, compreendida como a aplicação de técnicas derivadas do conhecimento científico, é o espaço de desenvolvimento das competências, capacidades e atitudes profissionais. Essa instrumentalização, geralmente, é situada no final dos cursos, momento em 
que o aprendiz já adquiriu os conhecimentos científicos básicos para lidar com as referidas ferramentas. Ao conceber a competência profissional como um conjunto de fatos e princípios, regras e procedimentos, a prática é considerada como um processo de preparação técnica, que possibilita a aquisição de habilidades e do funcionamento de regras para atuar em sala de aula. Sabemos que as heranças pedagógicas, veiculadas pela escola, nem sempre produziram um projeto vigoroso que pudesse superar essa dicotomia.

Atualmente, inúmeras universidades começam a vivenciar mudanças em seu projeto educativo, no âmbito da formação inicial ou continuada, especialmente, configurando o estágio numa dimensão investigativa e voltada para a busca de novas concepções da profissão docente e do processo ensino-aprendizagem, sedimentando práticas mais referenciadas pelos quatro princípios da aprendizagem (DELORS, 2000): saber, saber fazer, saber ser, saber conviver. Um projeto de pesquisa que envolve o aluno com todos os programas disciplinares vai tomando corpo e ao longo do curso, transformando-se em uma unidade investigativa dos problemas colocados pelo cotidiano escolar. Alterando o eixo teoria e prática, cria-se um novo processo de aprender a profissão docente que ultrapassa antigos modelos de formação centrados nas disciplinas e no professor. Porém, o novo desafio colocado por tais propostas, mais centradas na pluralidade de aprendizagens que o futuro professor vai efetivando ao entrar em contato com a realidade onde irá atuar, é que não se pode ignorar que 0 aprendiz de professorjá tem incorporado suas crenças e esquemas a respeito de como atuar na escola. A utilização de bons filtros teóricos, nesse espaço investigativo, possibilitaria, assim, um avanço nesses novos processos formativos.

A alteração principal desses novos projetos parece recair sobre o eixo ensino-aprendizagem. Os antigos modelos de formação davam ênfase maior aos conteúdos e ao professor-transmissor, colocando no ensino a ênfase no conhecimento. Hoje, com a tendência voltada aos processos de aprendizagem, muito pouco tem se falado sobre o principal desse processo, o aluno que aprende, como aprende enquanto sujeito didático, numa situação específica de ensino e aprendizagem. Ao mostrar a especificidade da pedagogia enquanto ciência da educação, PIMENTA (1997) destacou bem a explicação de ESTRELA (apud PIMENTA, 1997) quanto à omissão da pedagogia:

Por exemplo, na situação escolar, o "irredutível pedagógico" é o aluno, isto é, o indivíduo numa situação específica de ensino e aprendizagem. Diferente, portanto, das "ciências da educação", que estudam a criança, o jovem, o adulto etc. em si. Conseqüentemente, o campo da pedagogia (ciência da educação), no caso da educação escolar, é o ato pedagógico que envolve o aluno, 0 saber, o professor, a situação institucional etc., no qual a análise do comportamento em situação sobrepõe-se à análise do comportamento em si, o que significa uma modificação radical da fundamentação epistemológica e da prática da investigação na pedagogia (PIMENTA, 1997: 38). 
Essa ambigüidade, no campo da ciência da educação, compromete de uma certa maneira a própria identidade profissional docente, particularmente, na universidade com incipientes referências sobre os alunos, levam os docentes a planejarem um ensino para 0 aluno abstrato. A mudança de eixo do processo formativo requer uma análise mais consistente da situação do sujeito da formação, sujeito que irá acomodar sua condição de aluno à sua história pessoal de vida.

A prática docente, por se tratar de uma prática social, conscientemente desenvolvida, só pode ser entendida a partir de uma clara definição da sua área problemática que é a relação teoria e prática. Ela não existe sem algum conhecimento sobre a situação de atuação e alguma idéia do que seja o ensino. Neste sentido, seus praticantes devem possuir alguma teoria prévia que subsidie suas atividades e guie suas ações. Portanto, uma prática não existe separadamente de uma teoria. A teoria da prática docente não existe, portanto, num vazio teórico. Como produto das tradições existentes, ela é construída a partir dos conceitos que são privilegiados nos contextos histórico-sociais. Assim, os fossos abertos entre teoria e prática, entre a teoria educativa e a sua aplicação só existem por falta de uma reflexão dos próprios docentes, acerca de suas atividades profissionais. Considerar que esses hiatos sejam problemas de comunicação ou de implementação é concordar que os mesmos possam ser resolvidos com a aplicação de uma teoria na prática, fornecendolhe regras para a ação, sem a necessidade de se desocultar as circunstâncias históricas em que foram gerados.

Pesquisa realizada por Hoy y Woolfolk (apud GARCÍA, M.:1994) sobre crenças de professores em formação constatou que ao finalizar as práticas de ensino, os estudantes adotaram crenças mais conservadoras e mais voltadas para o controle dos alunos. A literatura de investigação tem considerado que as práticas de ensino (estágios supervisionados), compreendidas como um período de socialização profissional, têm contribuido para que os formandos sejam mais autoritários, impessoais, burocráticos e controladores, na medida em que se deparam e convivem com uma cultura escolar na qual os professores são pressionados a favor da ordem, controle e cumprimento de objetivos instrumentais.

Para CARR e KEMMIS (1988), a teoria educativa é aquela que guia a vida docente. Ela não é uma "teoria aplicada" que "bebe" de outras teorias das ciências sociais, mas possui uma identidade própria, que precisa ser desvelada mediante a avaliação crítica da idoneidade dos conceitos, das crenças, hipóteses e valores incorporados pelas práticas vigentes. Sua validade se encontra no fato de a mesma estar relacionada às experiências e situações concretas dos professores e em buscar soluções para as mesmas. Conceber a formação nesta perspectiva é pensar no professor como um inquiridor rigoroso de sua própria prática, no sentido de fortalecer-se profissionalmente, melhorando sua 
imagem e sua atuação, ao mesmo tempo em que vai construindo uma nova epistemologia capaz de integrar a teoria e a prática de forma científica. Para que isto ocorra, ele deverá não somente criticar os elementos insatisfatórios do pensamento prático, como, também, apontar soluções para sua eliminação.

Se é difícil compreender a especificidade dessa profissão, não é simples para o professor refletir sobre sua própria prática. Por se tratar de um "métier"complexo, denominado por Freud de "missão impossível", PERRENOUD (1997) reitera em seus escritos que pensar a formação de professores é pensar na complexidade de uma profissão que interage com polaridades como sucesso/insucesso do próprio aluno e do próprio empreendimento educativo. $\mathrm{O}$ professor trabalha num espaço de conflitos e muitas incertezas. A cada dia, ele se defronta com situações imprevisíveis que suscitam decisões urgentes. Dentre outras, decidir sobre o avanço do programa ou atender às necessidades dos alunos? Respeitar a identidade do aluno ou transformá-la? Desenvolver autonomia ou conformismo? Enfatizar os saberes, os métodos ou os valores, a educação, a socialização? Valorizar a competição ou a cooperação? Preferir a estruturação do pensamento e da expressão ou encorajar a criatividade e a comunicação? Corrigir provas ou preparar as aulas? Refletir sobre suas condições de trabalho ou encontrar estratégias de ensino que motivem um aluno que se recusa a aprender?

O cotidiano escolar desafia o professor a reconstruir, a cada dia, sua própria política de educação, sua pedagogia, sua didática, ampliando sua epistemologia de saberes, aperfeiçoando as relações que estabelece com os alunos e com os saberes, revendo sua ética profissional. Nesse trabalho diversificado e complexo, o professor vai construindo um repertório pessoal de conhecimentos práticos sobre a maneira de bem conduzir seu trabalho que não está apoiado em um modelo linear, mas cíclico, para não perder de vista sua intenção maior que são as aprendizagens dos alunos. É, e será sempre um eterno aprendiz de seu ofício, em termos de mobilização de múltiplos e complexos saberes.

Para Tardif, os cursos de capacitação docente têm um impacto pequeno sobre as crenças que os professores incorporaram em sua história de vida e trajetória escolar.

Na verdade, eles terminam sua formação sem terem sido abalados em suas crenças, e são essas crenças que vão reatualizar no momento de aprenderem a profissão na prática, crenças essas que serão habitualmente reforçadas pela socialização na função de professor e pelo grupo de trabalho nas escolas, a começar pelos pares, os professores experientes.

Mas haverá uma formação capaz de prepará-lo para sintonizar o tem- 
po previsto para o ensino com o tempo da aprendizagem do aluno, para lidar com um grupo de alunos que ele não escolheu e que pouco conhece, de lidar com tantas diferenças que apresentam o grupo-classe, de fazer uma transposição didática coerente com as necessidades dos alunos sem contrariar o projeto da escola? De saber, afinal, refletir e sistematizar sua própria prática, transformando-a em saberes que possam ser legitimados pelos seus pares? Enfim, quais saberes estaríamos realmente mobilizando em termos de competência profissional para "agir na urgência e decidir na incerteza"?

\section{Afinal, por que tratar dos saberes docentes?}

Quais implicações do que se refletiu sobre a relação entre os saberes docentes e os processos formativos podemos extrair para os docentes universitários?

Primeiro, que a profissão docente é um processo contínuo que não se esgota na formação inicial. Por se tratar de uma prática social, ela tem uma área problemática que é a relação teoria e prática, espaço conflituoso em que se alojam ideologias e relações de poder. Abrir este espaço à reflexão é uma via possibilitadora para se investir numa teoria educativa voltada para a eliminação dos mitos e preconceitos em torno da profissão e dos saberes docentes e, conseqüentemente, para tornar a prática de sala de aula mais "profissional". As novas tendências de formação do professor caminham no sentido da valorização profissional a partir dessa reflexão do "conhecimento prático", enquanto elemento fundamental e estruturador de novas propostas de formação. Opondo-se ao paradigma da racionalidade técnica, que aprimora técnicas, mas esvazia o pensar sobre o fazer, o que é suscitado hoje é a reflexão sobre a ação, não de modo assistemático, mas com registros e sistematizações que possam retornar à prática, em forma de teoria, com triangulação metodológica na análise de dados que permita incorporação de evidências procedentes de fontes diversas, colocando o professor no seu verdadeiro papel, não apenas de ator, mas de produtor do conhecimento sobre sua profissão. Um dos aspectos mais importantes das novas tendências é a utilização da pesquisa qualitativa para o desvelamento do cotidiano escolar e das múltiplas relações que os saberes docentes estabelecem na sedimentação da indissociabilidade entre ensino, pesquisa e extensão, acenando mudanças efetivas no cenário pedagógico das universidades.

Outra implicação é que um trabalho dessa natureza não se faz isoladamente, como se construiu durante os séculos anteriores, a "gramática geradora da escola" (NÓVOA, 1992). Se hoje essa grámatica define o saber-fazer em termos de utilização de tecnologias inovadoras, mais do que instrumentalização técnica, necessitamos de habilidades intelectuais para lidar 
com as informações, o que requer epírito crítico e compromisso político, dimensões essenciais na reorganização dos saberes da experiência.

Nesses tempos, em que o professor tem perdido sua voz e sua vez, é necessário, sim, que ele atue como inquiridor de sua própria prática, não de forma isolada, mas interagindo com seus pares, num exercício contínuo de trocas efetivas, de experiências compartilhadas. Para Tardif (1999), essa tarefa é urgente no meio universitário, especialmente, entre os professores da educação. Realizar pesquisas sobre suas próprias práticas de ensino contribui para o reconhecimento de que temos uma prática de ensino e de que somos, realmente, profissionais de ensino. À medida que for construída uma rede de auto-reflexão, igualmente vai sendo construída, com autenticidade, uma prática coerente com uma educação democrática. É nesse movimento que o professor poderá resgatar, junto com sua autonomia docente, a sua identidade profissional e, discutir, junto à comunidade escolar, a definição de políticas mais claras e de projetos mais orgânicos que possam responder aos desafios colocados pela sociedade atual.

Estes avanços, certamente, poderão balizar mudanças nas práticas pedagógicas do professor universitário, porém, tal utopia irá requerer outras estratégias ousadas que neguem a manutenção de uma profissionalidade guiada pelo modelo de competência profissional alojado na racionalidade técnica do atual projeto político educacional brasileiro, que utiliza a lógica do mercado para excluir a ética da educação superior.

\section{Nota bibliográfica}

1. Em 1998 havia 165.122 professores atuando no ensino superior brasileiro. Fonte: Inep/MEC/Seec. Censo do Ensino Superior. Brasil, 1998. Brasília: MEC/Inep. 1999.

\section{Referências Bibliográficas}

CARR, W. e KEMMIS, S. Teoría crítica de la enseñanza : la investigaciónaçción en la formación del profesorado. Barcelona: Martinez Roca, 1988.

CANDAU, V. M.( Org.). A Didática em questão. Petrópolis, Vozes, 1984.

CHEVALARD, Y . La transposition didactique: du savoir savant au savoir enseigné. Grenoble, La Pensée Sauvage, 1985.

CUNHA, M. I. e LEITE, D.B.C. Decisões pedagógicas e estruturas de poder na universidade. Campinas/SP: Papirus, 1996. 
DELORS, Jacques. Educação: um tesouro a descobrir. $4^{a}$ ed. São Paulo: Cortez, Brasília, DF: MEC: UNESCO, 2000.

GARCÍA, C. M. Formación del profesorado para el cambio educativo. Barcelona, PPU S. A ., 1994.

GOMEZ, Angel I.Pérez. «A formação de professores: novas perpectivas baseadas na investigação sobre o pensamento do professor» In: NOVOA, A . (Coord). Os professores e sua formação. Lisboa, Dom Quixote, 1992, pp. 93- 114.

INSTITUTO NACIONAL DE ESTUDOS E PESQUISAS EDUCACIONAIS . Diretoria de

Informações e Estatísticas Educacionais ( Inep/ MEC/ Seec) . Censo do Ensino Superior. 1998: Brasilia: Inep, 1999. http://www.inep.gov.br

NÓVOA, A . (Coord. ). Os professores e sua formação. Lisboa, Dom Quixote, 1992.

PERRENOUD, PH. La formation des enseignants entre théorie et pratique. Paris: Éditions L'Harmattan, 1994.

. Práticas Pedagógicas, Profissão Docente e Formação: perspectivas sociológicas. Lisboa: Publicações Dom Quixote, 1993. 1997.

. Pédagogie differenciée: des intentions à l' action . Paris: ESF Éditeur,

PIMENTA, S. G. ( Org.). Didática e formação de professores: percursos e perspectivas no Brasil e em Portugal. São Paulo: Cortez, 1997.

TARDIF, M. "Os professores face ao saber: esboço de uma problemática do saber docente". In: Teoria e Educação , n. 4, Porto Alegre: Pannonica, 1991, p. 215- 233.

. "Saberes profissionais dos professores e conhecimentos universitários". Quebec, CRIFPE 1999. 